DOI: https://doi.org/10.24127/ajpm.v10i2.3685

\title{
DESKRIPSI KEMAMPUAN PEMECAHAN MASALAH SISWA SMP DITINJAU DARI DISPOSISI MATEMATIS
}

\author{
Ida Yuliani ${ }^{*}$, Tri Atmojo Kusmayadi ${ }^{2}$, Farida Nurhasanah ${ }^{3}$ \\ ${ }^{1 *, 2,3}$ Universitas Sebelas Maret, Surakarta, Indonesia \\ ${ }^{*}$ Corresponding author. \\ E-mail: $\quad$ Idayulianii07@gmail.com ${ }^{1 *}$ \\ $\underline{\text { tri.atmojo.kusmayadi@staff.uns.ac.id }}^{2)}$ \\ farida.nurhasanah@staff.uns.ac.id ${ }^{3)}$
}

Received 20 April 2021; Received in revised form 15 June 2021; Accepted 29 June 2021

\begin{abstract}
Abstrak
Penelitian ini bertujuan untuk mendeskripsikan kemampuan pemecahan masalah matematis siswa ditinjau dari disposisi matematis. Penelitian dilakukan di kelas VIII B SMP Takhassus Al Qur'an Pekuncen. Subjek penelitian adalah enam siswa yang diambil dari kategori disposisi matematika tinggi, sedang, dan rendah. Data diambil dari hasil angket disposisi matematis, hasil tes dan hasil wawancara kemampuan pemecahan masalah. Hasil dari penelitian ini adalah siswa dengan kemampuan disposisi matematis tinggi memiliki kemampuan yang baik dalam memahami masalah terbukti dari hasil wawancara, menuliskan hal yang diketahui dan ditanyakan dengan bahasanya sendiri tetapi belum menuliskannya secara lengkap. Tepat dalam merencanakan penyelesaian, perhitungan dan pelaksanaan rencana sehingga memperoleh hasil yang benar. Tahap memeriksa kembali tidak dilaksanakan oleh siswa dengan kemampuan disposisi tinggi kecuali merasa ada keganjilan pada solusi yang diperoleh. Siswa dengan kemampuan disposisi matematis rendah sudah berusaha menuliskan data yang diperoleh dalam bahasanya sendiri tetapi membutuhkan stimulus pertanyaan pada saat wawancara, kurang tepat dalam merencanakan solusinya, perhitungan dan memanfaatkan data sehingga menghambat tahap melaksanakan rencana. Siswa dengan kemampuan disposisi matematis rendah memerlukan perhatian khusus dari guru karena masih kesulitan memahami masalah sehingga tidak dapat melewati empat tahapan pemecahan masalah. Siswa dengan kemampuan disposisi matematis sedang dan rendah tidak melaksanakan tahap memeriksa kembali.
\end{abstract}

Kata kunci: Disposisi matematis; kemampuan pemecahan masalah; matematika.

\begin{abstract}
The purpose of this study was to describe students' mathematical problem solving abilities based on their mathematical dispositions. The study was conducted in class VIII B of SMP Takhassus Al Qur'an Pekuncen. The subjects of this study were six students who were taken from the high, medium, and low mathematics disposition categories. The data were taken from the results of the mathematical disposition questionnaire, the test results and the results of the interview on problem solving abilities. The results of this study are students with high mathematical disposition abilities have good abilities in understanding the problems problems from the results of interviews, write things that are known and asked in their own language but have not written them completely. Be precise in planning completion, calculation and execution of plans so as to obtain correct results. The reexamination stage was not carried out by students with high dispositional abilities unless they feel that there was an obstacle in the solution obtained. Students with low mathematical disposition abilities have tried to write down the data obtained in their own language but require stimulus questions at the time of the interview. They-were inaccurate in planning solutions, calculating and utilizing data so that it hinders the planning stage. Students with low mathematical disposition abilities need special attention from the teacher because they still have difficulty understanding the problem so they could not pass the four stages of problem solving. Students with medium and low mathematical disposition abilities did not carry out the rechecking stage
\end{abstract}

Keywords: Mathematical disposition; mathematics; problem-solving.

This is an open access article under the Creative Commons Attribution 4.0 International License 
DOI: https://doi.org/10.24127/ajpm.v10i2.3685

\section{PENDAHULUAN}

Matematika merupakan mata pelajaran yang sudah dikenalkan sejak pendidikan sekolah dasar pada pembelajaran formal. Mempelajari matematika yang merupakan organisasi secara terstruktur akan membentuk pola pikir kritis, kreatif, logis, dan sistematis (Salistiyani et al., 2016). Pola pikir tersebut merupakan pola pikir yang dibutuhkan dalam mengembangkan keterampilan abad 21, terutama keterampilan pemecahan masalah. Salah satu tujuan mempelajari matematika adalah untuk mengembangkan kemampuan pemecahan masalah meliputi kemampuan memahami masalah, merencanakan peneyelesaian, melaksanakan rencana dan menafsirkan solusi (Permendikbud Nomor 58 tahun, 2014).

Kemampuan pemecahan masalah dalam matematika menurut (Ulya, 2016) adalah kemampuan seseorang dalam mengaplikasikan pengetahuan yang dimiliki dengan kondisi baru yang melibatkan proses berpikir tingkat tinggi. Kemampuan pemecahan yang mumpuni dapat mempermudah menyelesaikan masalah-masalah dalam kehidupan sehari-hari.

Salah satu faktor yang mempengaruhi kemampuan pemecahan masalah adalah aspek afektif (Maamin et al., 2021). Aspek afektif merupakan keterlibatan watak dalam ranah berpikir (Syafi'i et al., 2018). Rasa tekun dan percaya diri dalam menyelesaikan masalah matematika terdapat pada siswa yang memiliki aspek afektif (Rahman \& Kharisudin, 2020).

Kemampuan disposisi matematis merupakan salah satu dari aspek afektif yang memiliki pengaruh terhadap pemampuan pemecahan masalah (Kurniawan \& Kadarisma, 2020; Syarifah et al., 2018). Hasil dari penelitian (Kurniawan \& Kadarisma,
2020) menjelaskan bahwa siswa SMP yang memiliki disposisi baik akan cenderung percaya diri, fleksibel dalam menetapkan strategi, gigih dalam mencari solusi dan sistematis serta prosedural dalam menyelesaikan masalah matematika (Kurniawan \& Kadarisma, 2020).

Kenyataan dilapangan berdasarkan hasil PISA tahun 2018 masih tergolong rendah, indikator matematika memperoleh jauh dibawah rata-rata yaitu 379 (OECD, 2019). Data tersebut merupakan potret nyata rendahnya kemampuan siswa dalam menyelesaikan soal-soal non rutin, terutama soal pemecahan masalah. Sejalan dengan penelitian (Sholihah \& Afriansyah, 2018) menjelaskan bahwa dalam menyelesaikan masalah siswa masih kesulitan menerapkan ide matematika.

Hasil observasi awal yang dilakukan di SMP Takhassus Al Qur'an Pekuncen melalui wawancara dengan guru matematika mengatakan bahwa dari 25 siswa terdapat lima siswa yang melampaui KKM untuk PAT 2020/2021. Sedangkan 20 siswa mendapatkan nilai dibawah KKM. siswa yang memperoleh nilai dibawah KKM sering tidak mengumpulkan tugas-tugas dan mengerjakan soal yang diberikan. Mereka tidak percaya diri dan tidak merasa mampu menyelesaikan soal tersebut, serta mereka menganggap matematika itu sulit dipelajari. Respon negatif siswa terhadap matematika tersebut akan berpengaruh terhadap kemampuan pemecahan masalah matematis siswa.

Latar belakang tersebut menjadi motivasi untuk menganalisis kemampuan pemecahan masalah siswa SMP Takhassus Al Qur'an Pekuncen ditinjau dari Disposisi Matematis. Penelitian serupa dilakukan oleh (Akbar et al., 2017; Dinia et al., 2019; Hajar \& 
Sari, 2018; Rosita \& Yuliawati, 2016) yang dilaksanakan sebelum pandemi Covid-19 sehingga keterampilan pemecahan masalah yang dimiliki siswa adalah hasil dari pembelajaran tatap muka. Sedangkan penelitian ini dilaksanakan pada saat pembelajaran daring akibat pandemi covid-19 dan penelitian seperti ini pertama kalinya dilaksanakan di SMP Takhassus Al Qur'an Pekuncen.

Hasil dari penelitian ini diharapkan dapat menjadi potret nyata nyata kemampuan pemecahan masalah matematis siswa ditinjau dari disposisi matematis sehingga memudahkan guru mengenal siswa lebih baik dan memilih model pembelajaran yang tepat untuk meningkatkan kemampuan pemecahan masalah siswa.

\section{METODE PENELITIAN}

Model penelitian ini adalah deskriptif kualitatif yang bersifat menganalisis kemampuan pemecahan masalah matematis siswa SMP Takhassus Al Qur'an Pekuncen. Subjek penelitian adalah kelas VIII yang terdiri dari 45 siswa. Waktu pelaksanaan pada bulan April tahun pelajaran 2020/2021. Intrumen yang digunakan dalam penelitian ini adalah (1) Tes yang memuat dua soal uraian untuk mengukur kemampuan pemecahan masalah matematis, (2) Wawancara tidak terstruktur digunakan untuk membandingkan data dan menelusuri lebih dalam kemampuan pemecahan masalah subjek, (3) Angket disposisi matematis, (4) Observasi dilaksanakan untuk mengetahui situasi dan kondisi selama pembelajaran. Hasil jawaban siswa dianalisis melalui empat tahap pemecahan masalah (Polya, 1973) yaitu memahami masalah, merencanakan penyelesaian, melaksanakan rencana dan memeriksa kembali.
Instrumen yang digunakan dalam tes kemampuan pemecahan masalah adalah sebagai berikut :

1. Perhatikan gambar kubus berikut.

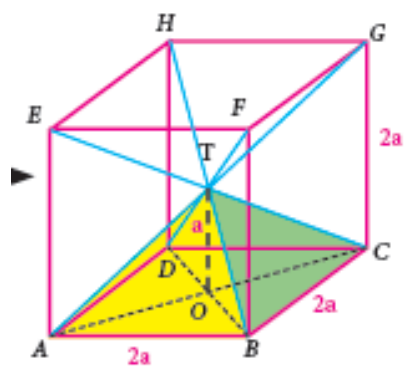

Hasna memanfaatkan wadah berbentuk kubus yang transparan untuk dijadikan jam pasir. Kubus sudah diberi sekatsekat dan salah satu limas akan diisi penuh dengan pasir seperti pada gambar. Jika nilai $a=3 \mathrm{~cm}$ maka volume limas yang berisi pasir adalah

2. Aruna mempunyai kawat sepanjang 2,4 $m$ yang digunakan untuk membuat kerangka kubus dan balok. Jika balok yang akan dibuat berukuran $15 \mathrm{~cm} \times$ $10 \mathrm{~cm} \times 8 \mathrm{~cm}$, panjang rusuk kubus maksimal yang dapat dibuat adalah ....

3. Azizah mempunyai toples berbentuk balok berukuran $10 \mathrm{~cm} \times 7 \mathrm{~cm} \times$ $15 \mathrm{~cm}$ yang diisi penuh dengan gula pasir. Gula pasir tersebut akan dipindahkan seluruhnya ke dalam toples berbentuk prisma yang memiliki luas alas $100 \mathrm{~cm}^{2}$ dan tinggi $15 \mathrm{~cm}$. Tinggi gula pasir pada toples berbentuk prisma tersebut adalah ....

Selain itu, indikator dan angket disposisi matematis yang digunakan dalam penelitian ini merupakan hasil modifikasi dari instrumen penelitian (Wahyuni, 2015). Berikut indikator disposisi matematis yang digunakan:

1. Percaya diri

2. Rasa ingin tahu

3. Fleksibilitas

4. Tekun

5. Reflektif 
DOI: https://doi.org/10.24127/ajpm.v10i2.3685

6. Mengaplikasikan matematika dalam kehidupan sehari-hari.

Angket disposisi matematis berisi dari 26 butir pernyataan dengan 12 pernyataan posisif dan 14 pernyataan negatif. Skala disusun dengan berpedoman pada skala Likert dengan empat pilihan jawaban. Bobot penilaian pada angket disposisi matematis diadopsi dari instrumen penelitian (Aliah et al., 2020) seperti terdapat pada Tabel 1.

Tabel 1. Bobot penilaian pada angket disposisi matematis

\begin{tabular}{clcc}
\hline No & \multicolumn{2}{c}{ Pernyataan } & \multicolumn{2}{c}{$\begin{array}{c}\text { Bobot Pernyataan } \\
\text { Positif }\end{array}$} & \begin{tabular}{c} 
Negatif \\
\hline 1
\end{tabular} & $\begin{array}{l}\text { Sangat } \\
\text { (SS) }\end{array}$ & & 1 \\
2 & Sesuai & 4 & \\
3 & Tesuai (S) & 3 & 2 \\
& $\begin{array}{l}\text { Tidak Sesuai } \\
\text { (TS) }\end{array}$ & 2 & 3 \\
4 & $\begin{array}{l}\text { Sangat Tidak } \\
\text { Sesuai (STS) }\end{array}$ & 1 & 4 \\
\hline
\end{tabular}

Hasil dari jumlah skor dari setiap responden lalu dihitung dikelompokkan sesuai dengan pengkategorian angket disposisi matematis yang bisa dilihat pada Tabel 2.

Tabel 2. Pengkategorian angket disposisi matematis

\begin{tabular}{ccc}
\hline No & Persentase & Kategori \\
\hline 1 & $73,91 \leq x$ & Tinggi \\
2 & $56,59 \leq x<73,91$ & Sedang \\
3 & $x<56,59$ & Rendah \\
\hline
\end{tabular}

\section{HASIL DAN PEMBAHASAN}

Data pengkategorian disposisi matematis dari hasil pengisian angket dapat dilihat pada Tabel 1. Enam subjek yang terpilih dari 25 siswa adalah kategori disposisi matematis tinggi yaitu HD-01 dan HD-02, kategori disposisi matematis sedang yaitu MD-01 dan MD-02, dan kategori disposisi matematis rendah yaitu LD-01 dan LD02 .

Tabel 1. Pengkategorian disposisi matematis.

\begin{tabular}{ccc}
\hline No & Kategori Disposisi & Jumlah Siswa \\
\hline 1. & Tinggi & 5 \\
2. & Sedang & 17 \\
3. & Rendah & 3 \\
\hline Jumlah & & 25 \\
\hline
\end{tabular}

Hasil tes kemampuan pemecahan masalah dan wawancara yang dilakukan kepada enam subjek dapat dideskripsikan sebagai berikut :

\section{Disposisi Matematis Tinggi}

Memahami Masalah

HD-01 dan HD-02 pada sesi wawancara dapat menjelaskan dengan benar dan lengkap apa yang diketahui pada soal. HD-01 menuliskan dengan bahasanya sendiri melalui gambar atahu kalimat yang mudah dipahami olehnya, sedangkan HD-02 menuliskan dengan menggunakan kalimat matematika yang jelas dan benar. Menurut HD-01 menuliskan apa yang diketahui dan ditanyakan secara lengkap dan terstruktur akan menyita waktu. Jawaban HD-01 dan HD-02 dapat dilihat pada Gambar 1 dan Gambar 2.

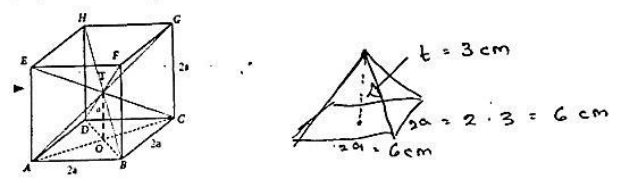

$$
\begin{aligned}
& \text { Jika } a=3 \mathrm{~cm} \text { maka tentukan volume limas yang ada pada kubus tersebut. } \\
& \text { Rumus limas: } \\
& \frac{1}{3} a \times t \\
& \frac{1}{3}(6 \cdot 6) \times 3 \\
& \frac{1}{7} \not 6 \times 3 \\
& 12 \times 3 \\
& 36 \mathrm{~cm}
\end{aligned}
$$

Gambar 1. Jawaban HD-01 nomor 1 
DOI: https://doi.org/10.24127/ajpm.v10i2.3685

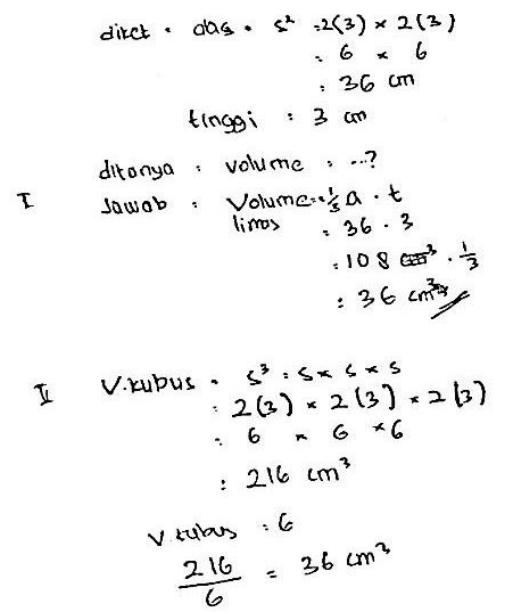

Gambar 2. Jawaban HD-02 nomor 1

Merencanakan Penyelesaian

Hasil dari wawancara bahwa HD01 dan HD-02 dapat menjelaskan rencana penyelesaian dengan benar. HD-01 bahkan menjelaskan melakukan kesalahan dalam menuliskan rumus balok namun segera diperbaiki setelah merasa ada keganjilan terhadap solusi yang diperoleh.

\section{Melaksanakan Rencana}

HD-01 telah melaksanakan rencana dan perhitungan yang benar sehingga memperoleh solusi yang tepat. Hasil wawancara HD-01 menjelaskan bahwa melaksanakan rencana dua kali pada soal nomor 2 karena ada kesalahan pada tahap membuat rencana penyelesaian. Sedangkan HD-02 menjelaskan bahwa dia salah dalam memanfaatkan volume balok yang sudah didapat untuk memperoleh tinggi gula pasir pada toples prisma soal nomor 3 .

\section{Memeriksa Kembali}

HD-01 melakukan pengecekan ulang pada nomor 2 karena merasa ada keganjilan pada solusi yang diperoleh. Hasil dari wawancara HD-02 tidak berniat untuk memeriksa ulang tetapi dia mempunyai dua ide penyelesaian pada soal nomor 1 .

\begin{abstract}
Berdasarkan semua aspek kemampuan pemecahan masalah, terlihat bahwa rasa percaya diri yang dimiliki oleh siswa dengan kemampuan disposisi tinggi memiliki pengaruh yang baik untuk kemampuan pemecahan masalahnya, mereka dengan percaya diri mampu menjelaskan.
\end{abstract}

\section{Disposisi Matematis Sedang \\ Memahami Masalah}

MD-01 dan MD-02 menjelaskan dengan benar apa yang diketahui dan ditanyakan tetapi harus diberi stimulus pertanyaan agar penjelasannya lengkap. keduanya belum bisa mengubah apa yang mereka ketahui menjadi kalimat matematika. Hal tersebut dapat dilihat dari jawaban MD-01 pada Gambar 3 dan jawaban HD 02 untuk soal nomor 1 disajikan pada Gambar 4.

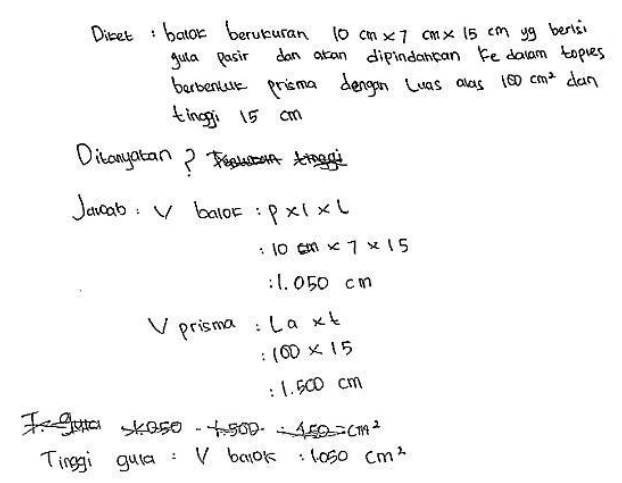

Gambar 3. Jawaban MD-01 nomor 3

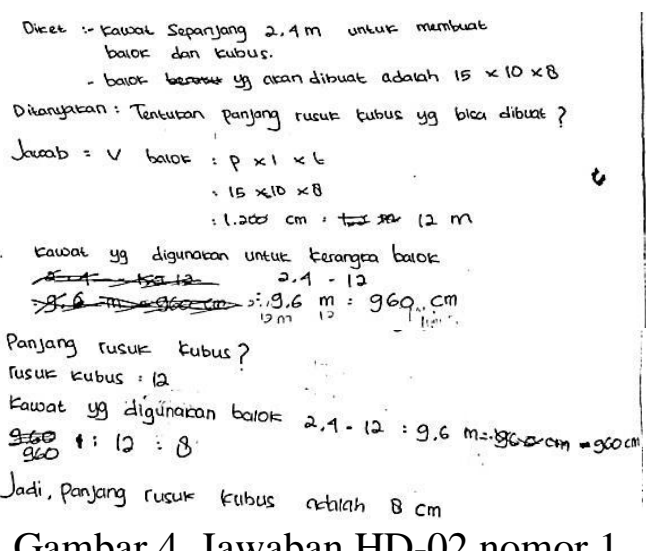

Gambar 4. Jawaban HD-02 nomor 1 
DOI: https://doi.org/10.24127/ajpm.v10i2.3685

Merencanakan Penyelesaian

MD-01 dan MD-02 mampu menyusun rencana dengan tepat soal nomor 1 dan nomor 3. Hasil wawancara MD-01 dan MD-02 menyadari telah melakukan kesalahan perencanaan pada soal nomor 2. Hasil dari wawancara, mereka sebenarnya kurang paham kapan harus menggunakan rumus volume dan panjang kerangka bangun ruang sisi datar. Hal tersebut berpengaruh terhadap ketepatan dalam penyusunan rencana, mereka menuliskan rumus yang sebenarnya tidak diperlukan dengan alasan bahwa yang mereka ingat adalah rumus tersebut.

\section{Melaksanakan Rencana}

MD-01 dan MD-02 pada saat wawancara dapat dengan benar menjelaskan penyelesaian nomor 1 sehingga memperoleh solusi yang tepat. MD-01 sudah tepat dalam perhitungan tetapi tidak dapat memanfaatkan data untuk menemukan solusi, hal tersebut bisa dilihat pada gambar 3 .

\section{Memeriksa Kembali}

MD-01 dan MD-02 tidak melakukan tahap memeriksa kembali karena mereka belum paham bahwa tahap memeriksa kembali penting dalam menyelesaikan masalah.

\section{Disposisi Matematis Rendah \\ Memahami Masalah}

LD-01 dan LD-02 tidak menuliskan data yang diketahui dan ditanyakan secara tepat dan lengkap. Hasil wawancara, keduanya membacakan soal untuk menjawab pertanyaan apa yang diketahui dan ditanyakan pada soal. LD01 dan LD-02 merasa tidak tertarik untuk menyelesaikan soal matematika dan merasa matematika sulit. Jawaban LD-01 dan LD-02 disajikan pada Gambar 5 dan 6.

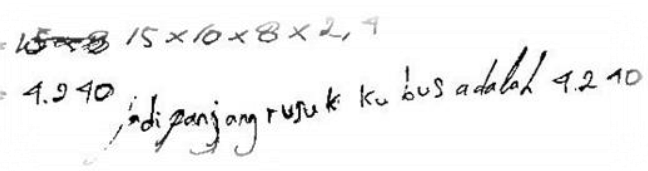

Gambar 5. Jawaban LD-01 nomor 2

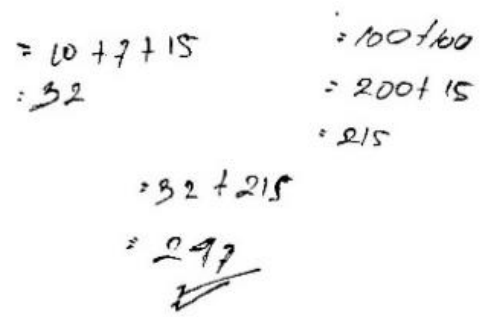

Gambar 6. Jawaban LD-02 nomor 3

LD-01 dan LD-02 tidak merencanakan penyelesaian dengan benar untuk soal no 1, 2 dan 3. LD-01 dan LD-02 mengabaikan langkah perencanaan penyelesaian sehingga tidak melakukan rencana penyelesaian. Mereka hanya mengoperasikan angka yang ada pada soal tanpa memberikan keterangan yang lengkap. Baik LD-01 dan LD-02 tidak melakukan langkah pemeriksaan ulang.

Hasil dari penelitian ini terlihat dengan jelas bahwa kategori disposisi tinggi, sedang dan rendah memiliki tahapan kemampuan pemecahan masalah yang berbeda-beda. Sependapat dengan (Hajar \& Sari, 2018) kategori disposisi matematis tinggi mempunyai kemampuan pemecahan masalah lebih baik dibandingkan kategori disposisi sedang dan rendah, serta semua kategori melewatkan tahap memeriksa kembali. (Hajar \& Sari, 2018) memberikan saran untuk memperkenalkan siswa kepada soal-soal pemecahan masalah, membuat bahan ajar yang baik, membimbing siswa dalam tahapan-tahapan pemecahan masalah, menggunakan beberapa pendekatan dan menggunakan media berbasis ICT. 
DOI: https://doi.org/10.24127/ajpm.v10i2.3685

\section{KESIMPULAN DAN SARAN}

Berdasarkan hasil penelitian dapat disimpulkan bahwa kendala yang dialami setiap kategori disposisi matematis beragam. Disposisi matematis sedang dan rendah merasa kesulitan dalam membuat model matematika, memilih dan menerapkan strategi, ketepatan dalam berhitung. Disposisis matematis rendah masih kesulitan dalam memahami masalah. Semua ketegori disposisi mengabaikan tahap memeriksa kembali, hanya disposisi matematis tinggi jika mendapati ada keganjilan pada jawaban. Faktor penyebabnya adalah : (a) siswa belum mahir dalam berhitung; (b) materi yang diajarkan sebelumnya tidak bermakna pada dirinya; (c) tidak terbiasa mengerjakan soal-soal kemampuan pemecahan masalah; (d) kesulitan dalam menggunakan data untuk menentukan strategi penyelesaian; (e) siswa belum merasa butuh materi matematika dalam kehidupan sehari-hari. Upaya yang dapat dilakukan adalah : (a) lebih dekat dengan siswa untuk menanyakan dan mendiskusikan kendala yang dihadapi; (b) berikan soal-soal secara bertahap agar semua siswa mendapat nilai yang bagus pada tahap pertama, diharapkan hal ini akan membangkitkan rasa percaya diri dan rasa mampu mengerjakan soal-soal matematika; (c) kenalkan soal-soal non-rutin secara bertahap; (d) latih siswa menggunakan tahapan-tahapan pemecahan masalah untuk menyelesaikan masalah; (e) gunakan model pembelajaran yang sesuai karakteristik siswa.

Adapun saran yang dapat disampaikan bagi peneliti/guru adalah (1) terus belajar untuk mengenal dunia siswa agar guru paham model pembelajaran yang menarik dan tepat untuk siswa, (2) setiap siswa adalah amanah dan setiap siswa itu unik, maka pahami terus karakteristik setiap siswa agar bisa lebih dekat dengan siswa.

\section{DAFTAR PUSTAKA}

Akbar, P., Hamid, A., Bernard, M., \& Sugandi, A. I. (2017). Analisis Kemampuan Pemecahan Masalah Dan Disposisi Matematik Siswa Kelas Xi SMA Putra Juang Dalam Materi Peluang. Jurnal Cendekia: Jurnal Pendidikan Matematika, 2(1), 144-153. https://doi.org/10.31004/cendekia. v2i1.62

Aliah, S. N., Sukmawati, S., Hidayat, W., \& Rohaeti, E. E. (2020). Analisis Kemampuan Pemecahan Masalah Matematika dan Disposisi Matematika Siswa pada Materi SPLDV. Jurnal Pembelajaran Matematika Inovatif (JPMI), 3(2), 91-98.

https://doi.org/10.22460/jpmi.v3i1. p91-98

Dinia, S., Nurhafifah, A. Y., Mayasari, M., Patimah, S., \& Hidayat, W. (2019). Analisis Kesulitan Kemampuan Pemecahan Masalah Matematis Ditinjau Dari Kemampuan Disposisi Matematis Siswa. Journal of Honai Math, 2(1), $\quad$ 65-76. https://doi.org/10.30862/jhm.v2i1. 59

Hajar, Y., \& Sari, V. T. A. (2018). Analisis Kemampuan Pemecahan Masalah Matematis Siswa Smp Ditinjau Dari Disposisi Matematis. Wahana Didaktika: Jurnal Ilmu Kependidikan, 4(2), 120-131. https://doi.org/10.31851/wahanadi daktika.v18i2.4387

Kurniawan, A., \& Kadarisma, G. (2020). Pengaruh Disposisi Matematis Terhadap Kemampuan Pemecahan Masalah Matematis 
DOI: https://doi.org/10.24127/ajpm.v10i2.3685

Siswa. Asimtot: Jurnal Kependidikan Matematika, 1(1), 41-49.

https://doi.org/10.30822/asimtot.v1 i1.97

Maamin, M., Maat, S. M., \& Iksan, Z. H. (2021). Analysis of the factors that influence mathematics achievement in the ASEAN countries. Cypriot Journal of Educational Sciences, 16(1), 371389.

https://doi.org/10.18844/cjes.v16i1 .5535

OECD. (2019). PISA 2018 Results (Volume I): What Students Know and Can Do. In OECD. OECD Publishing.

https://doi.org/https://doi.org/10.17

87/5f07c754-en

Permendikbud Nomor 58 tahun. (2014). Berita Negara Republik Indonesia. Menteri Kesehatan Republik Indonesia Peraturan Menteri Kesehatan Republik Indonesia, Nomor 65(879), 2004-2006.

Polya, G. (1973). How to Solve It. In Journal of Chemical Information and Modeling. Princeton University Press.

Rahman, A. A., \& Kharisudin, I. (2020). Analisis Kemampuan Pemecahan Masalah dengan Strategi Pemodelan Matematika pada Brain-Based Learning Berdasarkan Self-Efficacy. PRISMA, Prosiding Seminar ..., 3, 561-570.

Rosita, N. T., \& Yuliawati, L. (2016). Analisis Kemampuan Pemecahan Masalah Matematis. Jurnal Ilmiah Dikdaya, 6(1), 123-128.

Salistiyani, Usodo, B., \& Pramudya, I. (2016). Berdasarkan Taksonomi Solo Ditinjau Dari Tingkat Metakognisi Siswa Kelas X SMA Negeri 1 Cepu. Jurnal Elektronik
Pembelajaran Matematika, 4(9), 803.

Sholihah, S. Z., \& Afriansyah, E. A. (2018). Analisis Kesulitan Siswa dalam Proses Pemecahan Masalah Geometri Berdasarkan Tahapan Berpikir Van Hiele. Mosharafa: Jurnal Pendidikan Matematika, 6(2), 287-298. https://doi.org/10.31980/mosharafa .v6i2.317

Syafi'i, A., Marfiyanto, T., \& Rodiyah, S. K. (2018). Study Tentang Prestasi Belajar Siswa dalam Berbagai Aspek dan Faktor yang Mempengaruhi. Jurnal Komunikasi Pendidikan, 2(2), 115. Syarifah, F. S. ., Nuraidah, S., Riadjanto, M. L. E. ., \& Maya, R. (2018). Analisis Pengaruh Disposisi Matematis terhadap Kemampuan Pemecahan Masalah Matematis Siswa Smp. JPMI Jurnal Pembelajaran Matematika Inovatif, 1(2), 201-206. https://doi.org/10.22460/jpmi.v1i3. 219-228

Ulya, H. (2016). Profil Kemampuan Pemecahan Masalah Siswa Bermotivasi Belajar Tinggi Berdasarkan Ideal Problem Solving. Jurnal Konseling GUSJIGANG, 2(1), 90-96.

Wahyuni, E. T. (2015). Pembelajaran Berbasis Masalah untuk Meningkatkan Kemampuan Pemahaman, Pemecahan Masalah, dan Disposisi Matematis Siswa SMK. UPI Bandung. 